Figure 2. Change in SF-36 and FACIT-Fatigue at each visit

A)

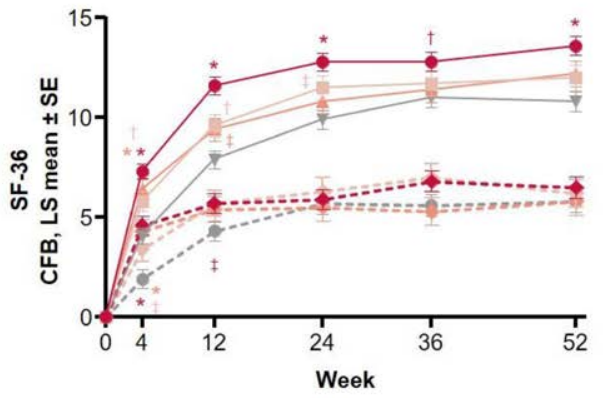

\begin{tabular}{|c|c|}
\hline PCS & MCS \\
\hline $200 \mathrm{mg}+\mathrm{MTX}=\mathrm{FIL} 200 \mathrm{mg}$ & $\leftrightarrow$ FIL $200 \mathrm{mg}+\mathrm{MTX} \leftrightarrow$ FIL $200 \mathrm{mg}$ \\
\hline$=$ FIL $100 \mathrm{mg}+\mathrm{MTX}+\mathrm{MTX}$ & $\Leftrightarrow \quad$ FIL $100 \mathrm{mg}+\mathrm{MTX}$ \\
\hline
\end{tabular}

B)

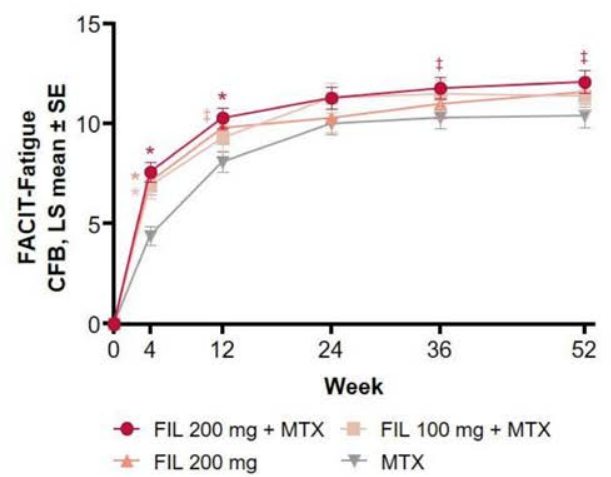

${ }^{*} p<0.001,{ }^{\dagger} p<0.01,{ }^{\ddagger} p<0.05$ for LS mean of the difference between FIL arm vs MTX. P values were not adjusted for multiplicity.

CFB, change from baseline; FIL, filgotinib; LS, least squares; MCS, mental component score; MTX, methotrexate; PCS, physical component score; SE, standard error.

Conclusion: For pts with moderate to severe RA who were MTX-naïve, FILwith or without concomitant MTX-led to more rapid and sustained improvements in functional status, pain, fatigue, and HRQoL, compared with MTX alone.

References:

[1] Van Rompaey, et al. J Immunol. 2013;131:3568-77.

[2] Westhovens, et al. Arthritis Rheumatol. 2019;71 (suppl 10):1606-8.

[3] Fautrel B, et al. Rheumatol Int. 2018;38:935-47.

[4] Smolen JS, et al. Ann Rheum Dis. 2017;76:960-77.

Disclosure of Interests: Rieke Alten Grant/research support from: Pfizer, Galapagos, Galapagos NV, Gilead, Gilead Sciences, Inc., Novartis, Consultant of: Pfizer, Speakers bureau: Pfizer, William Rigby Consultant of: Gilead Sciences, Inc., Alena Pechonkina Shareholder of: Gilead Sciences, Inc., Employee of: Gilead Sciences, Inc., Zhaoyu Yin Shareholder of: Gilead Sciences, Inc., Employee of: Gilead Sciences, Inc., Ken Hasegawa Shareholder of: Gilead Sciences, Inc., Employee of: Gilead Sciences, Inc., Thijs Hendrikx Shareholder of: Galapagos (share/warrant holder), Employee of: Galapagos, Tatsuya Atsumi Grant/research support from: Eli Lily Japan K.K., Alexion Pharmaceuticals, Inc., Bristol-Myers Squibb Co., AbbVie Inc., Daiichi Sankyo Co., Ltd., Pfizer Inc., Chugai Pharmaceutical Co., Ltd., Mitsubishi Tanabe Pharma Co., Astellas Pharma Inc., Consultant of: Gilead Sciences, Inc., Eli Lilly Japan K.K., UCB Japan Co. Ltd., AbbVie Inc., Daiichi Sankyo Co., Ltd., Pfizer Inc., Chugai Pharmaceutical Co., Ltd., Speakers bureau: Eli Lilly Japan K.K., UCB Japan Co. Ltd., Bristol-Myers Squibb Co., AbbVie Inc., Eisai Co. Ltd., Otsuka Pharmaceutical Co., Ltd., Daiichi Sankyo Co., Ltd., Pfizer Inc., Chugai Pharmaceutical Co., Ltd., Mitsubishi Tanabe Pharma Co., Takeda Pharmaceutical Co., Ltd., Astellas Pharma Inc., Rene Westhovens Grant/research support from: Celltrion Inc, Galapagos, Gilead, Consultant of: Celltrion Inc, Galapagos, Gilead, Speakers bureau: Celltrion Inc, Galapagos, Gilead

DOI: 10.1136/annrheumdis-2020-eular.2927

\section{FRI0116 \\ COMPARABLE EFFICACY AND SAFETY OF TWO REGIMENS OF RHEUMATOID ARTHRITIS TREATMENT WITH TOFACITINIB: DATA FROM RUSSIAN NATIONAL REGISTRY}

A. Babaeva ${ }^{1}$, E. Kalinina ${ }^{1}$, E. Nasonov ${ }^{2}$, V. Mazurov ${ }^{3}$, G. Lukina ${ }^{4}$,

A. Davydova ${ }^{5}$, I. Semizarova ${ }^{6}$, O. Slyusar ${ }^{7}$, T. Rasevich $^{8}$, R. Samigullina ${ }^{3}$,

D. Abdulganieva ${ }^{9}{ }^{1}$ Volgograd State Medical University, Volgograd, Russian

Federation; ${ }^{2}$ Nasonova Research Institute of Rheumatology, Moscow,

Russian Federation; ${ }^{3}$ Mechnikov North-Western State Medical University,

St-Petersburg, Russian Federation; ${ }^{4}$ Moscow Clinical Scientific and

Practical Centre named after Loginov AS, Moscow, Russian Federation;

${ }^{5}$ Kuban Regional Clinical Hospital 1 named after Ochapovsky, Krasnodar,

Russian Federation; ${ }^{6}$ Kuban State Medical University, Krasnodar, Russian Federation; ${ }^{7}$ State Health facility "City Clinical Emergency Hospital 25", Volgograd, Russian Federation; ${ }^{8}$ State Budzhet Healthcare Institution of the Astrakhan region Alexander- the Mariinsky Regional Hospital, Astrakhan, Russian Federation; ${ }^{9}$ Kazan State Medical University, Kazan, Russian Federation

Background: Current EULAR and national guidelines recommend use of synthetic target drug Tofacitinib (TOFA) for active rheumatoid arthritis (RA) treatment in case of resistance or intolerance to metotrexate (MTX) or other conventional DMARDs. Two treatment regimens are approved: TOFA mono-therapy and combination with conventional DMARD, preferably with MTX.

Objectives: Aim of presented study was to compare efficacy and safety of TOFA given in two regimens: as mono-therapy and in combination with MTX.

Methods: We analyzed data from Russian national registry of RA. 450 patients (pts) treated with TOFA in dose $10 \mathrm{mg}$ daily have been enrolled in this investigation. Among them 169 pts have composed TOFA mono-therapy group (mono) and 281 pts treated with TOFA plus MTX have been included in combo-therapy group (combo). Period of treatment varied from 6 months to 3 years and even more. Treatment efficacy was evaluated on the basis of clinical and laboratory indices of RA activity: CDAl, SDAl, DAS28, HAQ, GPA (general pain assessment), TJC, SJC, CRP, ESR monthly during first 6 months, than in 1,2,3 years and after 3 year period of treatment.

Results: There were no significant differences in pts demographic characteristic and disease longevity and/or severity in two separated groups. Majority of baseline indices were identical in these groups aside from SDAI, CRP (were higher in combo-group) and $\mathrm{HAQ}$ (was higher in mono-group). Pts monitoring have shown dramatically decrease of all used indices during the first several months of therapy in both groups. Moreover all clinical and laboratory parameters after 6-months treatment were comparable in mono- and combo- groups. Positive dynamics remained during further 3-year period in both groups. Significant differences between baseline and ultimate data after 3 year course therapy were revealed in CDAI, SDAI, DAS28, HAQ, GPA, TJC, SJC, CRP, ESR in both groups. In particular DAS28 index decreased from $5.38 \pm 0.08$ to $2.88 \pm 0.07(p<0.05)$ in mono-group and from $5.54 \pm 0.09$ to $3.40 \pm 0.21(p<0.05)$ in combo-group. Along with this comparing of endpoints in two analyzed groups have shown that levels of CDAI, SDAI, GPA were significant higher in combo-group than in mono-group $(p<0.05)$. Adverse effects were registered in $4.73 \% \mathrm{pts}$ from mono-group and in $4.98 \%$ pts from combo-group ( $p>0.05$ ). Spectrum of adverse reactions was similar in compared groups: respiratory infection (in $2.96 \%$ and $3.36 \%$ cases respectively) and herpes infection (in $0.59 \%$ and $0.71 \%$ cases, respectively) were registered predominantly.

Conclusion: Data gained from National RA registry have demonstrated that treatment with TOFA in mono-therapy regimen has the comparable efficacy with regimen of combined therapy, included MTX and TOFA. Safety of both regimens can be qualified as good. Obtained results confirm high efficacy and safety of target therapy with TOFA and prove the recommendation for use it in different regimens - mono-therapy or combination with MTX.

\section{References:}

[1] Smolen JS, et al. Ann Rheum Dis. 2017;0:1-18. doi:10.1136/annrheumdis2016-210715

[2] Boyle DL, etal.Ann Rheum Dis. 2015;74:1311-1316. doi:10.1136/annrheumdis2014-206028

Disclosure of Interests: Aida Babaeva: None declared, Elena Kalinina: None declared, Evgeny Nasonov Speakers bureau: Lilly, AbbVie, Pfizer, Biocad, R-Pharm, V Mazurov: None declared, Galina Lukina Speakers bureau: Novartis, Pfizer, UCB, Abbvie, Biocad, MSD, Roche, Antonina Davydova: None declared, Irina Semizarova: None declared, Olga Slyusar: None declared, Tatyana Rasevich: None declared, Ruzana Samigullina: None declared, Diana Abdulganieva: None declared

DOI: 10.1136/annrheumdis-2020-eular.3662 